\title{
XBRL Standard for Financial Reporting in Croatia: Current State and Perspectives
}

\author{
Dejan Gostimir \\ Zagreb School of Economics and Management, Zagreb, Croatia
}

\begin{abstract}
Background: Harmonization and standardization is becoming important among regulators and business community. XBRL has entered the global stage as a financial reporting standard. Its mission was to standardize the financial reporting, lower the reporting costs and make the reporting as transparent as possible. Objectives: The goal of the paper is to review the current usage of XBRL as a standard worldwide and to give an overview of its current state and perspectives in Croatia. Methods/Approach: The secondary research method for examining XBRL as a standard has been applied in this work. Results: The European Union embraced XBRL as the only standard that will be used for mandatory financial reporting and as such it is implemented in EU legislation. Croatia is a new member state and XBRL usage, which is still limited in Croatia, presents one of the country's challenges. Conclusions: $X B R L$ is the new standard for financial reporting that has had its place and usage in practice for several years now. It is adopted as a mandatory reporting standard in in most countries of the world, but not without barriers.
\end{abstract}

Keywords: eXtensible Business Reporting Language (XBRL), extensible markup language (XML), financial reporting standard, financial information, Europe, Croatia, perspectives

JEL classification: 014

Paper type: Research article

Received: May 11, 2015

Accepted: Jul 23, 2015

Citation: Gostimir, D. (2015), "XBRL Standard for Financial Reporting in Croatia: Current State and Perspectives", Business Systems Research, Vol. 6, No. 1, pp. 31-40.

DOI: 10.1515/bsrj-2015-0009

\section{Introduction}

In order to deliver and swap electronic data, corporations usually consume different data standards (Zhu \& Wu, 2014). Today, organizations' business and financial transactions are in digital format and all of the data flows inside the company databases (transactional database, accounting database etc.) and from one computer system to another (international companies subsidiary communication, different companies communication, etc.). Finally, financial transactions are aggregated in reports that are used for internal or external purposes. Reports are 
usually produced in various digital formats or in printed-paper copy. Different digital formats vary from Microsoft Word and Excel, Apple Pages and Numbers, Portable document format (PDF), Text format (TXT), Hyper Text Markup Language (HTML), or in special formats produced by different computer software. Mentioned formats are not unified or standardized, and without usage of proper software they cannot be read. Although different electronic data interchange (EDI) standards exist, they have trouble communicating with each other. In order to unify the standards, and to make all business and financial data readable, extensible Business Reporting Language (XBRL) was put in light as a solution for the problem and as a globally accepted standard.

XBRL standard is extended hypertext mark-up language that was invented by Charles Hoffman (certified public accountant) back in 1998, with the purpose of providing marks and labels for every single portion of data (business, tax, financial or textual) with the intention of cost efficient, rapid and simple examination and usage of data (Steenkamp \& Nel, 2012). "X" in XBRL stands for eXtensible which means that it can be used in a variety of reports and business data and information exchange. $X B R L$ originated from and is based on XML using the XML technology. XBRL standard and its technology is completely free of charge, there is no license fee because it is an open standard and everyone can use it.

Bar code made revolution in retail industry and now XBRL is compared to it, only now XBRL is revolutionizing the financial reports in a similar way (Stantial, 2007). XBRL standard brought innovation in the way organizations swap their corporate, economic, financial, tax and accounting data as a global standard (Bergeron, 2003). XBRL usage and awareness grows rapidly all over the world, whether it's been used for mandatory filling/reporting or as a pilot project. Acceptance of XBRL in European region also follows the rest of the world. Largely, this is linked to the fact that great expectation is placed on member states governments setting precise rules for financial sector. The rate of acceptance is also growing because of the convergence of International Financial Reporting Standards (IFRS) (Stergiaki, Stavropoulos \& Lalou 2013). But, the main reason lies in Revised Directive brought in 2013, on transparency requirements for listed companies (Transparency Directive) that states: "European Securities and Markets Authority (ESMA) should develop draft regulatory standards for adoption by the Commission, to specify the electronic reporting format, with due reference to current and future technological options, such as eXtensible Business Reporting Language (XBRL)".

The main focus of this paper is on XBRL standard characteristics, role and its usage, with the special focus on Croatia. Goal of the paper is to explore the current state and perspective of XBRL standard usage in Croatia. Research objectives that are intended to achieve are following:

- RO 1: To provide an overview of XBRL standard

- RO2: To explore available data on XBRL standard usage in European Union

- RO3: To uncover the current usage of XBRL standard in Croatia and its future perspectives

The article is organised as follows: XBRL standard is described in first section, second section gives an overview of its usage in European Union, and the third section gives an evaluation of the XBRL standard usage, while fourth section concludes the article and lists some perspectives.

\section{XBLR standard}

$X B R L$ standard is a stronger and more adaptable version of the XML language that is specially designed to meet the challenging needs of business and financial reporting 
(Stergiaki, Stavropoulos \& Lalou 2013). It allows the unique identification tags to be applicable on financial data (tangible assets, profit and loss, etc.). These identification tags are much more than a simple identifiers of financial data. Tags provide a lot of information about the data that are labelled, as for example they provide information whether the data is a monetary unit, the type of ISO currency, text, positive or negative number, percentages, decimals number, and so on. XBRL standard allows tags on almost any language; it also allows the use of different accounting standards and all sorts of information that are required in the reporting (Vasile, Petronel \& Georgel 2009).

XBRL standard shows the relationship between data and therefore can display how they are computed. It also identifies whether the data belong to a particular group for organizational needs or reporting purposes. Most importantly, XBRL standard is very easy to extend so different companies or organizations can customize standard to its requirements (Lampathaki et al., 2009).

Effective and valuable structure of the XBRL standard allows a very efficient management of enterprise data by a computer system, such as the compilation, storage and use of business data. Business and financial information can be converted in the XBRL standard with the appropriate mapping process or can be generated with appropriate XBRL software. Data converted into XBRL standard can then be searched, shared between different systems, analyzed or published to internet for browsing and viewing (Figure 1).

Figure 1

XBRL reporting distribution

National Tax Office

Data source

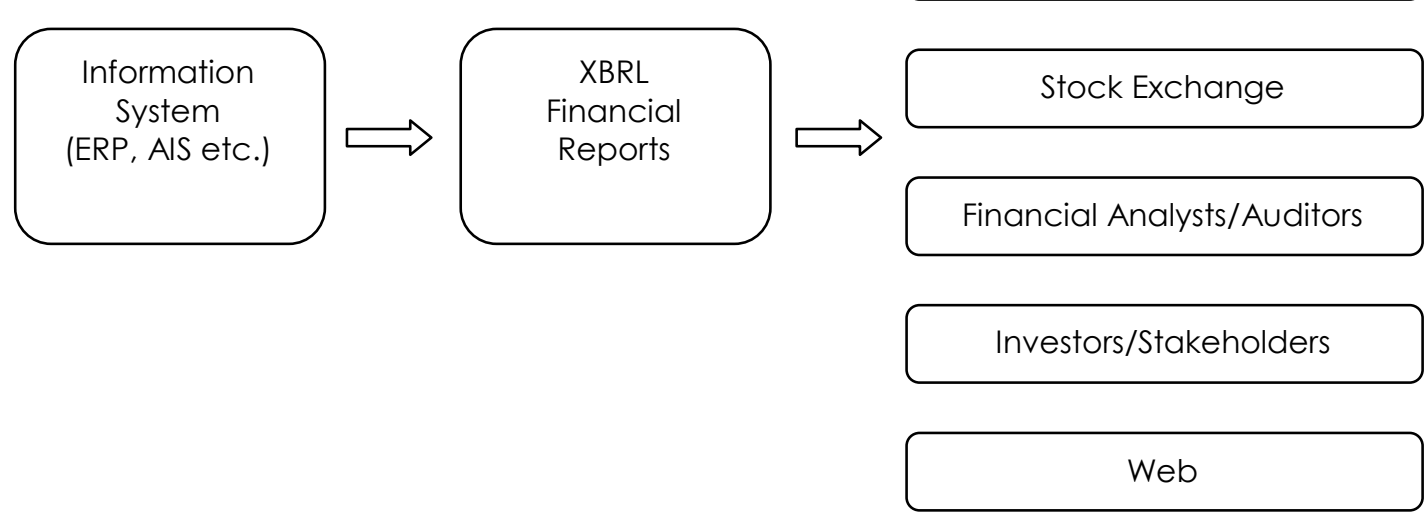

Source: Adapted from Vasile, Petronel \& Georgel (2009)

In order that all of the above can be implemented XBRL standard has its taxonomies or dictionaries. Taxonomies are categorization schemes that define a particular tag of individual data or element (depreciation, income tax, net income, and so on). Different countries may have different accounting standards and with the help of XBRL standard they can have their own taxonomy for financial reporting (Locke \& Lowe, 2007). Different companies, corporations, organizations and industries may also have taxonomies for their business needs and their internal reporting and consolidation. XBRL consists of a concept that describes a specific position in the financial report. Concepts have meaning with additional information and explicit connections between different concepts. Within the taxonomy there is assortment of 
all related concepts and taxonomy is a metadata framework for reporting. Numerical, monetary or text values are called values and are associated with the concept. In order that values and concepts obtain meaning they need additional information that will provide context. By combining the concept from taxonomy with a value and the necessary context the fact is created (Figure 2). The facts are presented in a document called instances. Instance documents are XBRL financial reports (Figure 3). Additional types of metadata are called dimensions, and they can be defined in the taxonomy and applied to instances as part of the context. Taxonomy can be extended for modifying the connections between existing concepts or to add new concepts to the existing taxonomy.

Figure 2

Example of concept and fact

\begin{tabular}{lr}
\hline Concept & Fact \\
\hline Liability & 2.000 \\
Company name & $\mathrm{ABC}$ Itd. \\
Profit & 1.000 \\
Date of the report & 31.12 .2013$. \\
\hline
\end{tabular}

Source: Author

The main objective of the XBRL standard is to reduce the production cost of information, to accelerate its flow, to increase the usefulness and globalize its form and content. Besides this main objective, many other advantages also emerge from the usage of XBRL.

First, all participants in the financial reporting chain can easily read, interpret and use XBRL documents. Second, it brings greater flexibility for investment and credit institutions that work with XML based applications, data warehouses and analytical tools. XBRL standard allows them to analyze data without re-entering the same data and analyses of data for multiple companies that listed or published their financial information in different formats. Finally, regulatory authorities can define specific taxonomies that describe financial information and use standard XML technology to acquire and processed the information.

Organizational costs that require preparing, sharing, storage and disclosure of information are drastically reduced because of the speed at which the data is compiled and prepared. Because of this the XBRL standard has obtained great benefits for all users of financial and business information, so the XBRL standard found its use in (Wallace, 2001): preparation of financial statements, consolidated financial statements of companies operating on a global level, tax returns, preparation and reporting of data for regulatory government agencies, internal reporting within the organization, particularly in developing managerial reports, analysis of companies, and assessing the credit risk and credit approval. 


\section{Figure 3}

Example of XBRL instance document

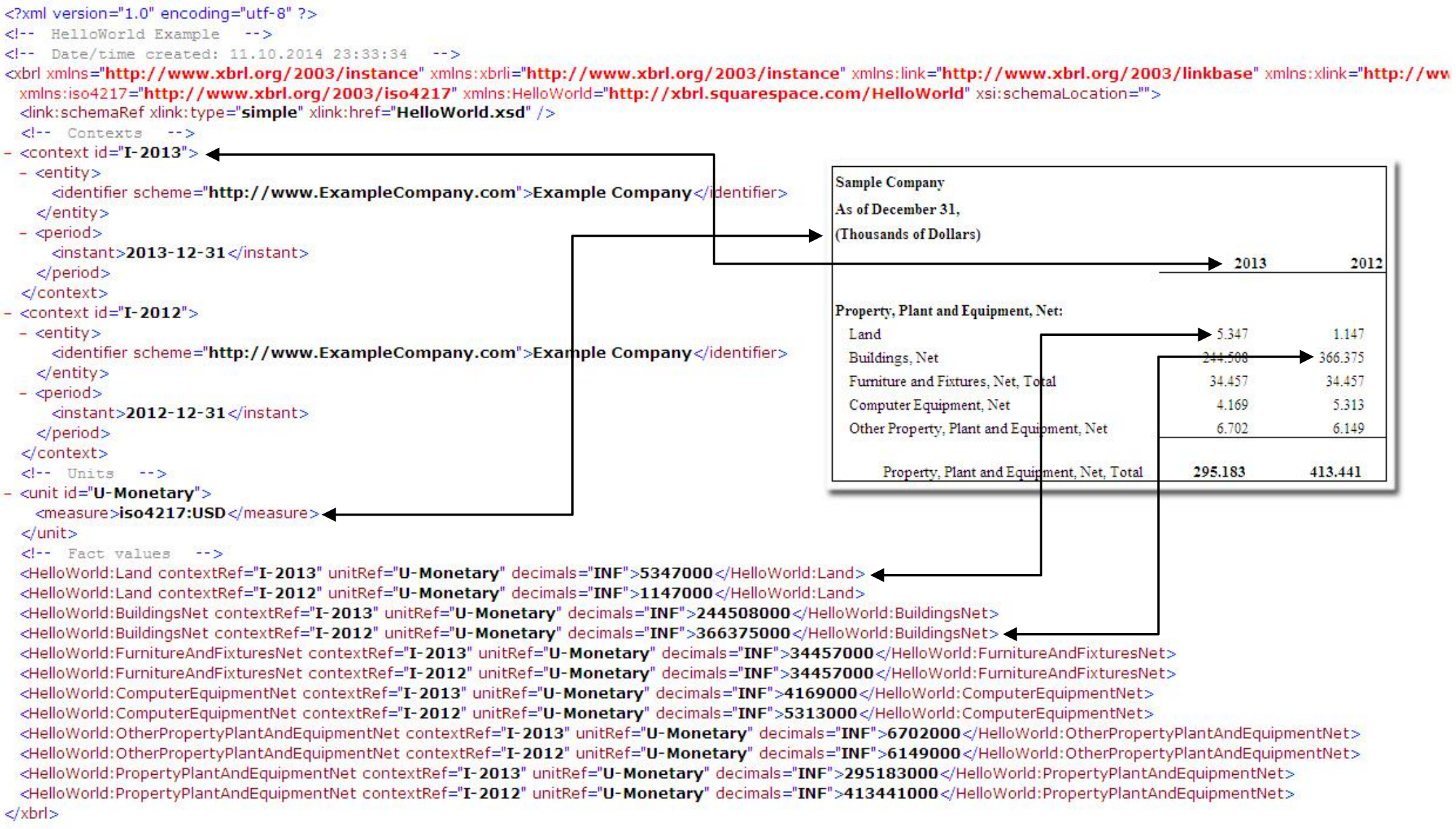

Source: Adapted from http://xbrl.squarespace.com/journal/2008/12/18/hello-world-xbrl-example.html 


\section{Evaluation of the XBRL standard usage}

\section{$X B L R$ standard usage in European Union}

Analysis of the literature demonstrates that XBRL is widely accepted, used and implemented all over the world and in EU member states. The type of implementation and usage vary from mandatory to voluntary and pilot projects. Committee of European Banking Supervisors (CEBS, now European Banking Authority - EBA) decided in 2004 to use XBRL standard as an interaction tool for financial organizations and national regulators in order to encourage solvency and solidity of the financial structure in European Union (Bonson, 2007). Common REPorting (COREP) and FINancial REPorting (FINREP) are two XBRL projects that were started by the Committee of European Banking Supervisors in order to ascertain harmonized financial reporting for regulator needs concerning solvency monitoring of financial and investment organizations across EU (Stefanescu, 2014). As part of the adoption of the COREP and FINREP framework across Europe, some countries have decided to use XBRL for their solvency and financial reporting (Figure 4).

Figure 4

COREP and FINREP usage in EU
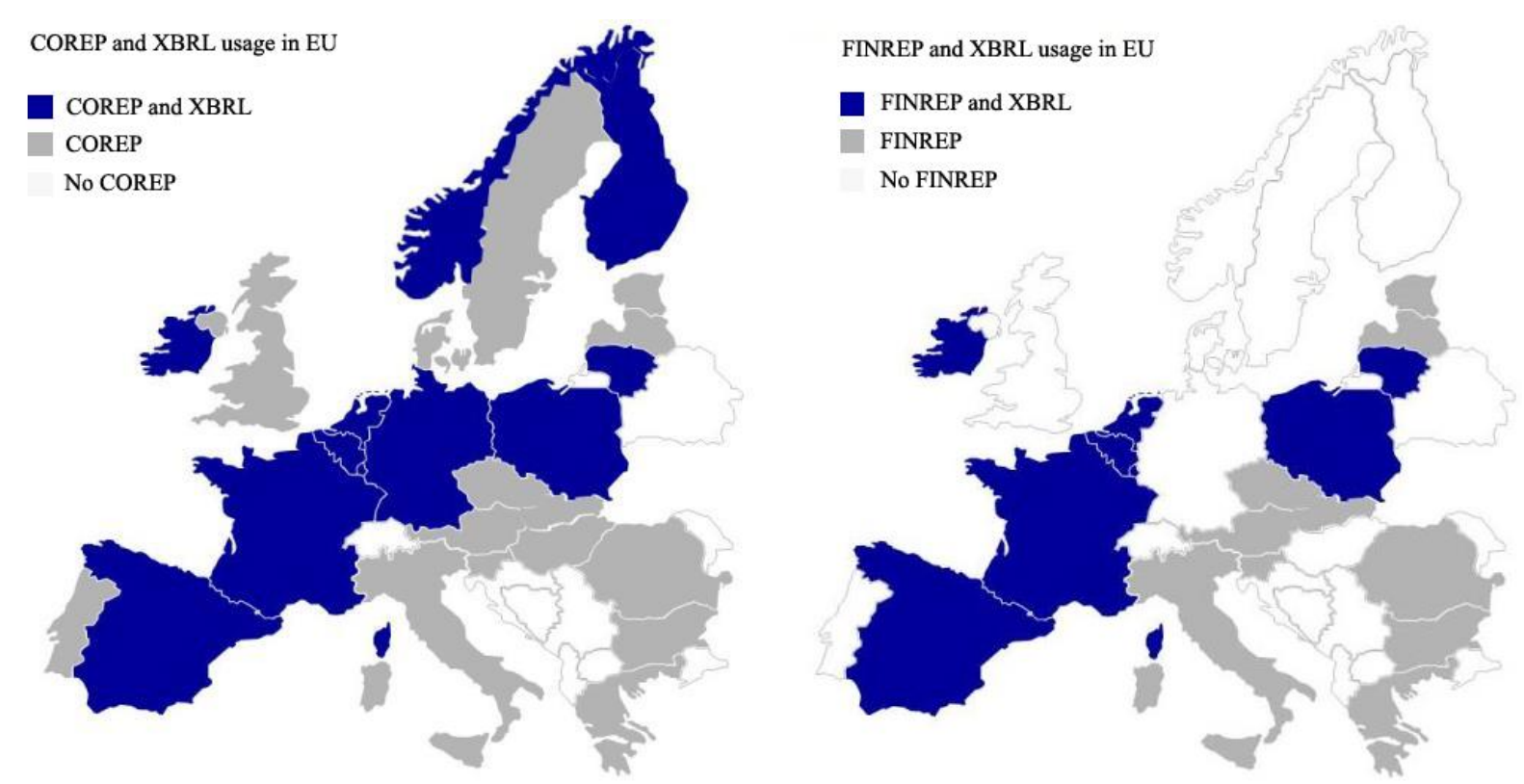

Source: Adapted from: http://www.eurofiling.info/

The COREP framework is used for providing regulation to market through transparency and provision for risk management (Stefanescu, 2014). Its main goal is "to reduce the reporting burden for credit institutions that operate cross-border and lower barriers to the development of an efficient internal market in financial services" (CEBS, 2007). International Financial Reporting Standards (IFRS) are the ground for FINREP framework that was constructed to direct to a common European reporting (Stefanescu, 2014).

XBRL standard is also used all over EU for disclosure of financial statements and some of the leading member states use it for the following purposes: National Bank of Belgium uses XBRL to collect balance sheet for 400.000 companies for statistical purposes. Danish Business Authority collects annual financial statements from all 
Danish companies in XBRL standard. The reports are used for purposes of registration and market information. UK uses XBRL to collect data from 2.2 million companies for tax filling purposes. The data is collected from UK's Her Majesty's Revenue \& Customs. Also, the data is collected from UK Companies House from 1.5 million companies for annual financial statements. Spanish Ministry of Economy, National Accounting and Auditing Institute collect XBRL data for annual financial reporting from all Spanish companies and Ministry of Finance from Germany collects XBRL data for tax returns for German companies.

\section{XBRL standard usage in Croatia}

Current usage in Croatia is on very low level since there are no mandatory requirements from regulators and also no ongoing pilot projects that could test XBRL in real life. The only current XBRL usage can be found with Croatian National Bank that uses COREP framework and XBRL for reporting towards EU regulator European Banking Authority (EBA).

According to Use of the Guidelines on Common Reporting and its application in the Republic of Croatia the COREP framework is used quarterly for supervision of credit institutions. Reporting towards Croatian National Bank applies to credit institutions with registered offices in the Republic of Croatia, authorized by the Croatian National Bank and to branches of third-country credit institutions, authorized by the Croatian National Bank to provide services. Accounting framework that is used for reporting is International Financial Reporting Standards (IFRS) and International Accounting Standards (IAS) and official reporting standard is XML. Credit institutions uses XML standard and Excel for reports toward Croatian National Bank which than aggregates data and converts it in XBRL standard in order to send XBRL reports to European Banking Authority. The same principle is used for FINREP reporting.

The Croatian Financial Services Supervisory Agency (HANFA) also considers XBRL. HANFA is a supervisory authority whose scope of activities and competence cover the supervision of financial markets, financial services and supervised entities providing those services. According to EU Directive 2013/50/EU that was published on $6^{\text {th }}$ November 2013; member states National legislation has 24 months deadline to implement the Directive. EU Directive 2013/50/EU prescribes the obligation for ESMA (European Securities and Markets Authority) to create a unique European Single Electronic Format (ESEF) which will be primarily related to the annual financial statements, the starting point for it is the XBRL; mandatory usage and application of the ESEF will be for the annual reports and it will start from 2020. ESMA is a supervising body of HANFA and according to that HANFA started to consider XBRL and the ways in which they will implement it in the reporting. Probably they will use the same principle as Croatian National Bank because it will be less resource and time consumable.

Other than those two examples there was no other information available for XBRL usage in Croatia except that several individuals and companies trying to promote it as a standard and that it is taught as an elective course at Zagreb School of Economics and Management.

\section{Perspectives of XBRL standard usage in Croatia}

Since recently Croatia is the member state of EU, perspectives of XBRL standard usage in Croatia may have a chance to drastically change to a wider usage. European commission promotes XBRL standard for usage not only with bank regulators, stock exchanges but also with tax offices among all member states. 
The ground for implementing XBRL standard in wider reporting usage already exis as Croatian National Bank uses it for reporting towards European Banking Authority. According to that the Croatian National Bank as a regulator for credit institutions can mandate XBRL as the only standard for reporting for credit institutions. Also, European Insurance and Occupational Pensions Authority (EIOPA) in its 2013 Guidelines on Submission of Information to National Competent Authorities talks about XBRL as a mandatory standard for reporting. This means that in very short period of time Croatian Financial Services Supervisory Agency (HANFA) will use XBRL as mentioned in the previous section of this article (Current usage in Croatia).

The next phase of XBRL implementation could be on Zagreb Stock Exchange as a pilot project for all listed companies through annual financial statement reporting. The EU and world stock exchanges were one of the first users of XBRL reports. Croatia has enough large companies that use large Enterprise Resource Planning from world known vendors. Most of that software has integrated XBRL modules by default and first pilot projects and reports could be finished and generated in no more than two years with reasonable collaboration among supervisor and listed companies.

Final phase of XBRL implementation could be at the Croatian Tax Office for company tax reporting since current reporting uses XML as a standard. Also, parallel with Croatian Tax office in the final phase of XBRL implementation, Croatian Financial Agency (FINA) could join the project, as it is the agency that collects yearly financial reports from the companies.

Tax office uses XML and its schemas as a standard for collecting VAT, Income Tax, Salaries and other prescribed forms for data collection from companies through online web form. Since all companies already use XML for mandatory tax reporting the conclusion is that there is a firm base for accepting XBRL as a standard for tax reporting. The first step for implementing XBRL on both sides is development of taxonomies for tax reporting in Croatia. After that, some major modification should be made to tax office information system in order for implementing taxonomies and all necessary changes. According to developed taxonomies and XBRL schemas local software vendors will be able to develop small software add-ins for existing software that would "translate" existing data into required XBRL reports or, tax office itself could develop such universal "translators" that would be freely distributed among companies. The implementation and development on tax office side could be done with a low cost since it could be done through public-private partnership with EU Project grants and financing. Low implementing costs will not have any major impact on the national budget and at the end the XBRL standard adoption and implementation will have major savings effect, lower costs of reporting, faster, safer, accurate and more transparent reporting system for regulators and reporting companies.

Same way could be used for FINA implementation since it provides companies with done Excel files for mandatory yearly financial statements reporting. Excel files are filled by companies and submitted to FINA electronically through web-based form. FINA could use the same Excel files with add-ins that would "translate" the reports to XBRL format and used for reporting and filling purposes.

Important step in XBRL standard adoption is forming the national XBRL Jurisdiction that would be promoting XBRL as a standard where stakeholders and regulators will be the ones who should start promoting XBRL as a reporting standard in Croatia since it could lower the reporting expenses, make it more transparent and harmonized with EU legislation (Figure 5). 
Figure 5

Proposed steps for adoption and implementation of XBRL standard in Croatia
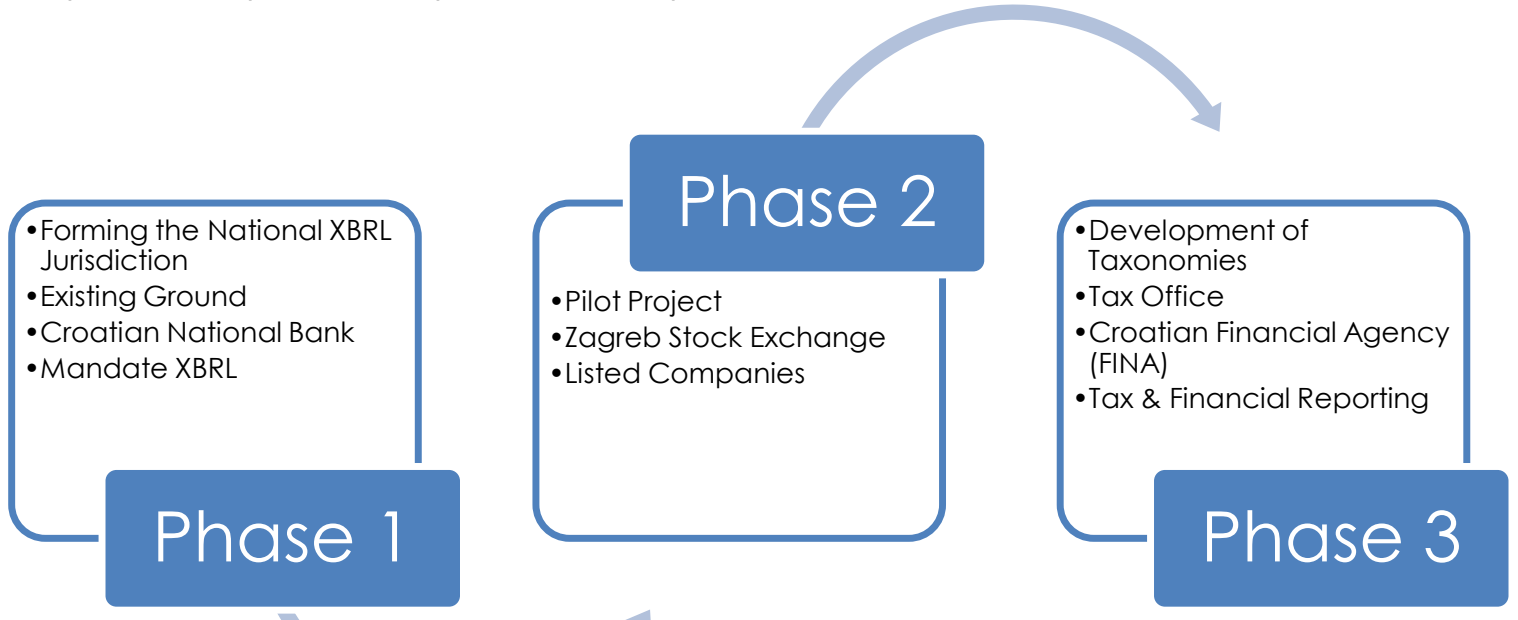

Source: Author

\section{Conclusion and further research}

As stated in previous chapters XBRL standard is more and more widely used for financial reporting because of its transparency, accuracy and cost effectiveness. (Troshani et al., 2015) As such it has become inevitable standard for financial reporting. Some European countries embraced it for mandatory and others for voluntary filling.

Whatever the usage form is, the conclusion is that it will spread to all member states because of the EU Directives and legislation. Unfortunately, Croatia is little bit running late with its adoption as a standard. The reason for that lies in low XBRL standard public awareness and in low awareness among business and regulatory community. Current usage of XBRL standard at the moment is only in bank and financial sector and if there were no EU legislative that prescribed that, there would probably be no usage at all. The implementation and adoption of XBRL standard in Croatia is very important because it would provide faster, cheaper and transparent financial reporting that would have a great positive impact on national budget and the economy itself. The proposed steps for adoption and implementation of XBRL standard in Croatia are: Forming the National XBRL Jurisdiction, have an Existing Ground, mandate XBRL from Croatian National Bank, and make the Pilot Project on Zagreb Stock Exchange with the Listed Companies, develop the Taxonomies and include Tax Office and Croatian Financial Agency (FINA)in XBRL Tax \& Financial Reporting.

Through our discussion and proposed steps for adoption and implementation of XBRL standard in Croatia we tried to address some important issues of its implementation and responsibilities of regulators. No standard is perfect and XBRL standard has more advantages than disadvantages (Wagenhofer 2007), considering that we are aware that our recommendations for Croatia can be improved and what is more important, they must be checked in practice. Further research of literature, case studies and implementation in other countries must be taken into account before considering adoption and implementation of XBRL standard in Croatia. 


\section{References}

1. Bergeron, B. (2003), Essentials of XBRL: Financial reporting in the 21st century, John Wiley \& Sons.

2. Bonson, P. E., Escobar, R. T., Flores, M. F. (2007), "The role of metadata language implementation in the European banking supervision network", International Journal of Networking and Virtual Organisations, Vol. 4, No. 3, pp. 245-256.

3. Lampathaki, F., Mouzakitis, S., Gionis, G., Charalabidis, Y., Askounis, D. (2009), "Business to business interoperability: A current review of XML data integration standards", Computer Standards \& Interfaces, Vol. 31, No. 6, pp. 1045-1055.

4. Locke, J., Lowe, A. (2007) "XBRL: an (open) source of enlightenment or disillusion?", European Accounting Review, Vol. 16, No. 3, pp. 585-623.

5. Stantial, J. (2007), "ROI on XBRL: Interactive data cuts reporting costs today", Journal of Accountancy, Vol. 32, pp. 34-35.

6. Steenkamp, L. P., Nel, G. F. (2012), "The adoption of XBRL in South Africa: an empirical study", Electronic Library, Vol. 30, No. 3, pp. 409-425.

7. Stefanescu, C. (2014), "XBRL-based projects for financial and prudential reporting-an empirical analysis in European banking system", Acta Universitatis Danubius, Economica, Vol. 10, No. 2, pp. 76-86.

8. Stergiaki, E., Stavropoulos, A., Lalou, T. (2013), "Acceptance and usage of extensible business reporting language: An empirical review", Journal of Social Sciences, Vol. 9, No. 2, pp. 1-14.

9. Troshani, I., Parker, L. D., Lymer, A. (2015), "Institutionalising XBRL for financial reporting: resorting to regulation", Accounting and Business Research, Vol. 45, No. 2, pp. 196-228.

10. Vasile, F., Petronel, A. C., Georgel, T. C. (2009), "The normalization of financial data exchange over the Internet: adopting international standard Xbrl", Annals of the University of Oradea, Economic Science Series, Vol. 18, No. 4, pp. 935-939.

11. Wagenhofer, A. (2007), "Economic consequences of internet financial reporting", in Debreceny, R., Felden, C., Piechocki, M. (Eds.), New Dimensions of Business Reporting and XBRL, Springer, pp. 99-123.

12. Wallace, A. (2001), "The new language of financial reporting", Balance sheet, Vol. 9, No. 2, pp. 29-32.

13. Zhu, H., Wu, H., (2014), "Assessing Quality of Large-Scale Data Standards: A Case of XBRL GAAP Taxonomy", Decision Support Systems, Vol. 59, pp. 351-360.

\section{About the author}

Dejan Gostimir is a Ph.D. student in Business Economy at the Faculty of Economics, University of Rijeka and the lecturer at the Zagreb School of Economics and Management. His research interests include XBRL, internal auditing, forensic accounting, accounting, controlling, IT and management. The author can be contacted at: dejan.gostimir@zsem.hr 